\title{
Attachment and Affective Temperament: Study of a Sample of Portuguese Higher Education Students
}

\author{
By Raul Cordeiro ${ }^{*}$
}

\begin{abstract}
This study aimed to study the relationship between attachment patterns (parental and loving) and affective temperaments (depressive, cyclothymic, hyperthymic irritable and anxious), conceptualized as either stable (depressive and hyperthymic) or unstable (cyclothymic, irritable and anxious). We collected data that allowed us to understand whether secure patterns of attachment correlate positively with stable temperaments. A correlational and exploratory study design was carried out with quantitative data from a sample consisting of 760 students of the nursing courses from four Portuguese polytechnic schools of higher education. The data were collected by selfreport questionnaire, consisting of several measures: socio-demographic variables, the Temperament Evaluation of Memphis, Pisa, Paris and San Diego (TEMPS-A), validation for the Portuguese population, the Father/Mother Attachment Questionnaire - QVPM, Version IV and the Love Attachment Questionnaire - QVA, Version III. Participants are mostly female (83.3\%) with an average age of 21.3 years, mostly living in a household with both parents; $81.7 \%$ have siblings and $60.3 \%$ have a dating relationship. Attachment patterns (secure, preoccupied, dismissing and fearful) were built from parental and loving attachment data. The results show significant associations between unstable temperaments (cyclothymic, irritable and anxious) and the dismissing pattern of parental attachment (father and mother).
\end{abstract}

Keywords: Affective temperament, Loving attachment, Mental health, Parental attachment

\section{Introduction}

The central problem of the current research is the analysis of the relationships between patterns and factors of parental and loving attachment and affectionate temperament, aiming at better understanding the phenomena of mutual moderation between these concepts in a young adult population.

This work focuses on theoretical formulations regarding affective temperaments identified by Hagop Akiskal and his colleagues (Akiskal 1985, 1994, Akiskal and Akiskal 2005a, 2005b, Akiskal et al. 2005a, 2005b, Akiskal et al. 1998), as well as those theoretical formulations regarding attachment (Bowlby 1978a, 1978b, 1979, 1980, 1984a, 1984b).

Akiskal and Akiskal (2005a) based their proposed model on the concept of predisposition of mood, a continuation of the studies led by Kraepelin (1913/19, 1921) and his observation of mood patterns in clinical practice. From their formulations, three primary types of temperaments emerged: the hyperthymic, the cyclothymic and the depressive. These were later supplemented with the anxious and irritable temperaments.

Akiskal and his colleagues have developed a classification framework of these temperaments (Akiskal 1985, 1994, Akiskal and Akiskal 2005a, 2005b) based, in the early stages of their studies, on the following typology:

- Depressive Temperament: individuals given to worry and tending to be pessimistic, quiet, timid, indecisive and passive. They have a reserved

\footnotetext{
* Associate Professor, Polytechnic Institute of Portalegre, Portugal.
} 
behaviour, are resigned, reflective and have high tolerance for monotonous situations or those that require caution.

- Cyclothymic temperament: individuals who alternate between periods of high and low self-confidence, lethargic and energetic states, confusing and sharp thoughts, playful and sad moods, introverted and expansive moments, drowsiness and little need for sleep.

- Irritable temperament: irritability traits as a marked and constant characteristic. These individuals are threatening, suspicious, combative and destructive.

- Hyperthymic temperament: dynamic individuals, wishing for stimuli and pleasure sensations, with a tendency to impulsiveness, curiosity, extravagance and disorganization. They wish for fast and intense affective reactions, are restless, bored and irritable.

In further studies, the anxious temperament would be added, characterized by an exaggerated personality disposition towards concern. It is characterized by anxious moods, with unpleasant feelings of anxiety expressed through tremors, sweating, or tachycardia, especially with anxious reactions in specific situations (such as tests, work, interviews, and social situations, among others).

In the context of attachment the researchers decided to choose two aspects of study: parental attachment (father and mother) and loving attachment. In the current study, this choice is justified because these aspects correspond to relevant stages identified in the continuum of human development and social relations.

With regard to attachment, the theory of Bowlby and Ainsworth (Ainsworth and Bowlby 1991) has been taken as a secure basis for the exploration of humanspecific developmental dynamics within the perspective of the life cycle, by making use of methodological diversity. The contributions of theory and research have been so relevant that, at present, attachment theory is taken as an extremely robust conceptual framework.

For Bowlby (1978a, 1978b), attachment experiments during childhood are internalized into internal working models that meet expectations of yourself and others. Bartholomew and Horowitz (1991) formed a dichotomous approach to these two dimensions of the self and the other into positive and negative, constructing a model of four prototypes of attachment. Thus, internal models of the self can be positive (the self as worthy of love and support) or negative (the self as unworthy of love and support) and internal models of the other may also be positive (others are responsive and reliable) or negative (others are rejecting and unavailable).

Bartholomew's model suggests certain characteristics for the Prototypes of Attachment. These descriptions are based on either that which is presented in the Peer Attachment Interview (Bartholomew 1996), various articles (Bartholomew 1990; Bartholomew and Horowitz 1991), or even in documents that are available at the website page of the laboratory directed by Kim Bartholomew herself at Simon Fraser University ${ }^{1}$.

\footnotetext{
${ }^{1}$ Bartholomew's Research Lab. www.sfu.ca/psyc/faculty/bartholomew/research/.
} 
The model of the self is associated with the-level of anxiety and dependence in close relationships; on the other hand, the model of the other is associated with the degree of responsiveness and availability or avoidance of others (Bartholomew and Shaver 1998). The intersection of these two types of models results in four attachment prototypes: secure, preoccupied, fearful and dismissing (Bartholomew and Horowitz 1991).

In Portugal the study of attachment in accordance with this conceptual model has been led by Paula Mena Matos and colleagues (Matos et al. 1999, Matos et al. 1997, 1998, Matos et al. 2001, Matos and Costa 2006). These studies utilized an instrument of self-reporting aimed at teenagers and young adults to assess their attachment to their parents - Father/Mother Attachment Questionnaire - QVPM, Version IV (Matos and Costa 2001a) - and an instrument for assessing loving attachment - the Love Attachment Questionnaire - QVA, Version III (Matos and Costa 2001b).

Temperament refers to an individual's emotional form, and it is regarded as the basis of mood, behaviour and personality (Lara 2006). It is related to the individual emotional nature, has predominantly genetic heritage, and is relatively stable over time (Allport 1961, Cloninger et al. 1993).

\section{Methodology}

A correlational, exploratory study was carried out through quantitative data analysis with the following objectives:

- to characterize the affective temperaments, conceptualized as stable and unstable;

- to characterize the parental and loving attachment factors and patterns;

- to correlate the affective temperaments with parental and loving attachment factors.

The following research hypotheses guided the study:

H1 - Secure parental attachment patterns are positively correlated with stable temperaments.

H2 - Secure loving attachment patterns are positively correlated with stable temperaments.

\section{Participants}

The sample of this study $(\mathrm{N}=836)$ was taken from the higher education population, specifically students of the Nursing degree from Central and Southern Portugal who were attending the following schools in the academic year of 2007/2008:

- Higher School of Health of Portalegre $(\mathrm{N}=255)$;

- S. João de Deus Higher School of Nursing - University of Évora (N = 123); 
- Higher School of Health of Beja $(\mathrm{N}=245)$;

- Dr. Lopes Dias Higher School of Health, Castelo Branco ( $\mathrm{N}=213)$.

The following criteria were defined for inclusion in the sample:

- Having answered the entire questionnaire;

- Being over 18 years old.

The exhaustive application of inclusion rules resulted in a study group of $\mathrm{N}=$ 760 respondents.

\section{Instruments}

The current study used the following measures included in the questionnaire referred to above:

\section{a) Parental Attachment Evaluation}

The Father/Mother Attachment Questionnaire - QVPM, Version IV (Matos and Costa 2001a) was used and applied in two ways: one related to the mother and the other to the father.

The QVPM is a self-response questionnaire constructed with the purpose of evaluating attachment representations that adolescents and young adults have regarding each of the parental figures (father and mother evaluated separately) (Moura and Matos 2008).

The QVPM is structured on a Likert-type ordinal scale (1 to 6), the value 6 being the value to indicate when the statement fully describes the respondent's opinion, and the value 1 to indicate when the assertion does not match the opinion of the respondent. The response format thus contains six implied hypotheses as choices: three of agreement (4 to 6 ) and three of disagreement (1 to 3).

It is composed of items organized in a bonding structure composed of 3 factors: inhibition of exploration and individuality (IEI), emotional bond quality (QLE), and separation anxiety and dependence (SAD).

The inhibition factor of exploration and individuality intends to evaluate the perception of restrictions on the expression of individuality. The quality factor of the emotional tie aims to evaluate the importance of the parental figure as a linking figure, perceived as fundamental and unique in the development of the subject, whom he will resort to in situations of difficulty and with whom he projects a lasting relationship. The anxiety factor of separation and dependence evaluates the experience of anxiety and fear during separation from the attachment figure as revealing of a relationship of dependence. The scale consists of 30 questions, each dimension being composed of 10 questions:

- Inhibition of exploration and individuality $(\mathrm{n}=10): 1,4,7,10,13,16,19$, 22, 25, 28;

- Quality of emotional bond ( $\mathrm{n}=10): 2,5,8,11,14,17,20,23,27,30$;

- Separation anxiety and dependence $(\mathrm{n}=10): 3,6,9,12,15,18,21,24,26$, 29. 
The psychometric qualities of this instrument have been tested using several independent samples, evidencing adequate validity and reliability indicators (Matos and Costa 2006).

In the most recent studies (Moura and Matos 2008), the three scales have quite acceptable Cronbach values. In the Pai version, the IEI scale has $\alpha=0.79$, the QEB $\alpha=0.94$, and the SAD $\alpha=0.86$. Regarding the Mother version, the IEI scale reveals $\alpha=0.80$, the QLE $\alpha=0.87$, and the SAD $\alpha=0.82$.

For this study, the three scales presented values of internal consistency (Cronbach's Alpha quite acceptable). Regarding the Mother version, the IEI factor presented $\alpha=0.85$, the factor QEB $\alpha=0,90$ and the SAD factor $\alpha=0,83$, for $\alpha=$ 0,81 for the total scale (linkage in the relationship with the mother).

In the Father version, the IEI factor showed $\alpha=0.85$, the factor QEB $\alpha=$ 0.95 , and the SAD factor $\alpha=0.87$, resulting in $\alpha=0.87$ for the full scale (linkage in the relation with the father).

\section{b) Loving Attachment Evaluation}

Love Attachment Questionnaire - QVA, Version III (Matos and Costa 2001b) is also structured on a Likert-type ordinal scale (1 to 6), with the value 6 being indicated when the statement fully describes the respondent's opinion, and the value 1 indicated when the assertion does not match the opinion of the respondent. The response format thus contains six implied hypotheses as choice: three of agreement (4 to 6) and three of disagreement (1 to 3 ).

The quality of the bonds is determined through 4 factors or dimensions: trust, dependence, avoidance and ambivalence in relation to the loving couple, as a linking figure.

The scale consists of 52 questions; each dimension being composed of 13 questions:

- Confidence ( $\mathrm{n}=13): 1,5,12,14 *, 17 *, 19,24 *, 29,35,37 *, 42,49 *, 52$ (* inverted items)

- Dependence ( $\mathrm{n}=13): 2,6,10,15,21,22,25,32,33,38,43,47,50$;

- Avoidance ( $\mathrm{n}=13)$ : 3, 7, 11, 16, 18, 23, 27, 30, 34, 40, 44, 45, 51;

- Ambivalence ( $\mathrm{n}=13)$ : 4, 8, 9, 13, 20, 26, 28, 31, 36, 39, 41, 46, 48.

In the scale validation studies (Matos et al. 2001), the internal consistency evaluation of the scale pointed to high values in all dimensions ( $\alpha$ between 0.75 and 0.90), with the ambivalence dimension showing the lowest consistency internally.

The QVA showed a good internal consistency evaluated by Cronbach's Alpha $(\alpha)$ with values between 0.85 and 0.91 for all dimensions: avoidance $(\alpha=$ $0.85)$, dependence $(\alpha=0.86)$, ambivalence $(\alpha=0.87)$ and confidence $(\alpha=0.91)$. 


\section{c) Affective Temperament Evaluation}

TEMPS-A is a measurement scale based on research of temperament literature, composed of 110 items and constructed to provide five temperamental dispositions or dimensions: depressive temperament - items 1 to 21 ( 21 items), cyclothymic temperament - items 22 to 42 (21 items), hyperthymic temperament items 43 to 63 (21 items), irritable temperament - items 64 to 84 (21 items, minus one for female gender) and anxious temperament - items 85 to 110 (26 items).

It is a "True" or "False" self-response scale, which assesses stable/ underlying characteristics related to one's temperament (e.g., I am by nature a disagreeable person; I am usually an upbeat and cheerful person). The score was obtained by using the value zero (0) for "False" and one (1) for "true" and consequently calculating a sum for each subscale.

Subjects with scores above the cut-off point of each subscale were considered to have excessive temperament: 13 points for the depressive temperament; 16 points for the cyclothymic; 20 for the hyperthymic; 12 for the irritable and 19 for the anxious (Figueira et al. 2008).

The validation study for the Portuguese language (Figueira et al. 2008) confirmed the five factors and presented a coefficient of internal consistency within the acceptable limit ( $\alpha=0.67$ to 0.83 ).

In the present study, the TEMPS-A scale revealed, in general, good internal consistency with a Cronbach's Alpha $(\alpha)$ of 0.87 for the full scale and a Cronbach's between 0.63 and 0.82 for the various temperaments as follows: $\alpha=$ 0.63 (depressant), $\alpha=0.82$ (cyclothymic), $\alpha=0.76$ (hyperthymic), $\alpha=0.75$ (irritable) and $\alpha=0.84$ (anxious) (Figueira et al. 2008, 2009), revealing a moderate to good consistency of the scale.

Given the fact that affective temperament subscales have different numbers of response items (depressive - 21 items, cyclothymic - 21 items, hyperthymic - 21 items, irritable - 21 items and anxious - 26 items), to obtain comparison factors between values of the five subscales of the temperament it was necessary to resort to the standardization of values.

The standardization of values of the subscales was obtained using Z-scores that define a degree of each temperament (Figueira et al. 2008). The concept of dominant temperament derives from the comparison of Z-scores obtained by each subject in all subscales of temperament. A range with variation above and below one (1) Z-score of the mean $(\mathrm{Z} 1=$ mean $\pm 1 \mathrm{DP})$ was defined as this value is considered the mean result of the population. The standardized results were graded as: slightly positive (Z1 to Z2), slightly negative (-Z1 to -Z2), moderately positive (> Z2), and moderately negative $(<-\mathrm{Z} 2)$. A cut-off point above 2 standard deviations was set in the consideration of dominant temperament (Figueira et al. 2008, Vahip et al. 2005).

\section{Procedures}

Data collection took place between January and June 2008. Data collection, through questionnaire completion, was conducted in the classroom with the presence of the investigator. The data collected for this study were launched and 
edited using the SPSS ${ }^{\circledR}$ (Statiscal Package for Social Sciences), version 17.0 database. When constructing the database, the variables needed for the study were coded, respecting their levels of measurement. All the ethical procedures required by the institutions at the date of the study were observed.

\section{Results}

\section{Socio-Demographic Variables}

The average age for the respondents was $\mathrm{M}=21.3$ years $(\mathrm{SD}=2)$, in total ranging between 18 and 36 years, with a median of 21 years. Males specifically ranged between 19 and 35 years with $\mathrm{M}=21.8(\mathrm{SD}=2.6)$ and a median of 21 years; females ranged between 18 and 36 years with $\mathrm{M}=21.2(\mathrm{SD}=1.9)$, also with a median of 21 years.

It was also found that $75 \%$ of the respondents were under 22 years of age, $50 \%$ were under 21 and $25 \%$ under 20, with an interquartile range of 2 years for females and 3 years for males.

Attachment with Mother

Graph 1. Dimensional Variability of the Attachment in the Relationship with the Mother

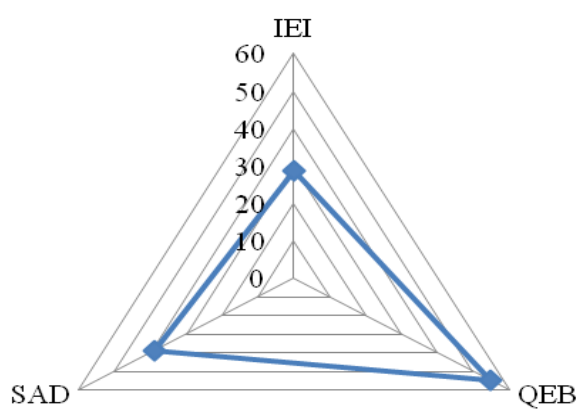

Graph 1 shows higher mean scores in the quality and emotional bond factor (QEB) in attachment with mother. The correlation values between the three factors revealed statistically significant results: (i) positive between the factors of separation anxiety and dependence (SAD) and quality of emotional bond (QEB) ( $\mathrm{r}$ $=0.476 ; \mathrm{p}=0.000$ ); (ii) negative between the quality of the emotional bond and inhibition of exploration and individuality $(r=-0.379 ; \mathrm{p}=0.000)$. No correlation with statistical significance was found between the inhibition of exploration and individuality (IEI) and separation anxiety and dependence (SAD) factors.

In the calculation of the mean results of the factors of attachment to the mother by gender the researchers observed higher mean results for the inhibition of exploitation and individuality (IEI) among males $(M=29.6, S D=(M=55.0$, $\mathrm{SD}=5.8)$ and for separation anxiety and dependence $(\mathrm{SAD})(\mathrm{M}=39.3, \mathrm{SD}=9.2)$ among females. 
The application of the t-test of equality of means for two independent samples allows us to verify that there are statistically significant mean differences between genders in the QEB $(\mathrm{t}=-2.850, \mathrm{p}=0.004)$ and SAD $(\mathrm{t}=2.527, \mathrm{p}=0.012)$.

The difference of means resulting from ANOVA (One-way) demonstrated that the effect of the variable of attachment patterns on the means of the factors of attachment to the mother was significant [inhibition of exploration and individuality $(\mathrm{F}=490.82 ; \mathrm{p}=0.000)$; quality of emotional bond $(\mathrm{F}=257.30 ; \mathrm{p}=$ $0.000)$; separation anxiety and dependence $(\mathrm{F}=382.65, \mathrm{p}=0.000)]$. Post hoc analyzes indicated that the safe pattern differed significantly from disinvestment and fear patterns in the IEI factor and disinterested, frightened, and worried patterns on QEB and SAD factors. Through Graph 2 it is possible to visualize the results of the construction of the clusters.

Graph 2. Attachment Patterns in the Relationship with the Mother

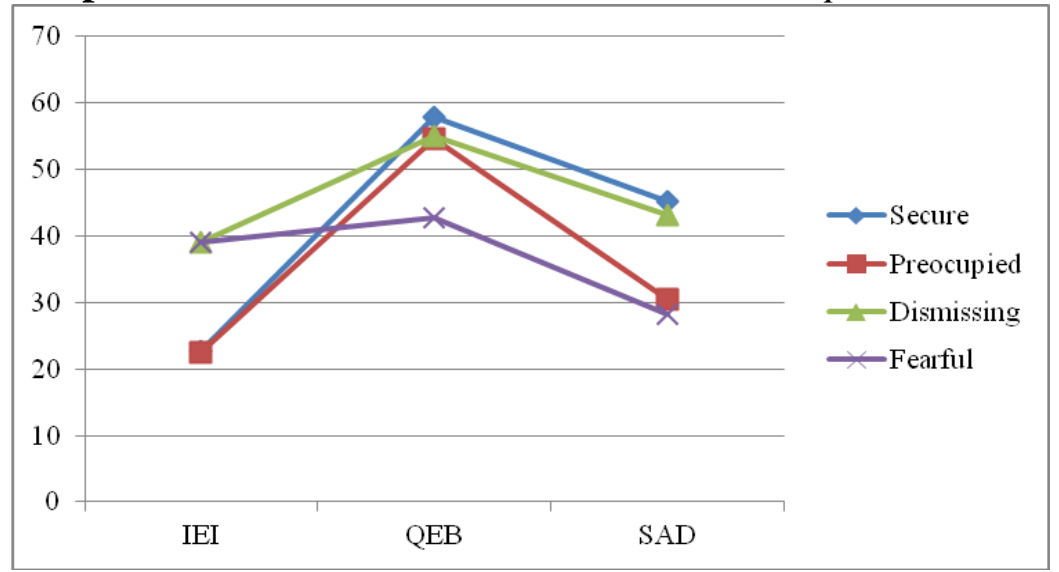

Note: Attachment factors in the relationship with the mother: IEI: Inhibition of Exploration and Individuality; QEB: Quality of Emotional Bond; SAD: Separation Anxiety and Dependency.

The differences in means obtained from the attachment patterns in the relationship with the mother have also shown that the quality of attachment is interpretable in light of the Bartholomew (Bartholomew and Horowitz 1991) model, as is readily observable from Graph 2.

\section{Attachment with Father}

Graph 3. Dimensional Variability of the Attachment in the Relationship with the Father

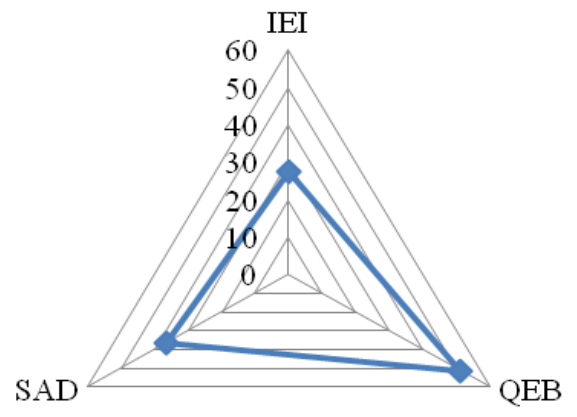


Graph 3 shows higher mean scores in the quality and emotional bond factor (QEB) in attachment with father.

The correlation values between the three factors revealed statistically significant results: (i) positive between the factors of separation anxiety and dependence (SAD) and emotional bond quality (QEB) $(r=0.657 ; \mathrm{p}=0.000)$; (ii) negative between emotional bond quality and inhibition of exploration and individuality $(r=-0.248 ; \mathrm{p}=0.000)$. No correlation with statistical significance was found between the factors of exploration inhibition and individuality (IEI) and separation anxiety and dependence (SAD).

In the calculation of the mean results of the father-to-gender factors, the researchers observed higher mean scores for the inhibition of exploration and individuality (IEI) among males $(\mathrm{M}=28.6, \mathrm{SD}=10.4)$ and for $(\mathrm{M}=51.5, \mathrm{SD}=$ $9.5)$, and separation anxiety and dependence $(\mathrm{SAD})(\mathrm{M}=36.9 ; \mathrm{SD}=10.0)$ among females.

The application of the t-test of equality of means for two independent samples allows us to verify that there are statistically significant differences between the sexes in QEB $(\mathrm{t}=-2.073, \mathrm{p}=0.038)$ and $\mathrm{SAD}(\mathrm{t}=-2.544, \mathrm{p}=0.011)$.

The difference of means resulting from ANOVA (One-way) demonstrated that the effect of the variable of attachment patterns on the means of the factors of attachment to the father was significant [inhibition of exploration and individuality $(\mathrm{F}=296.26 ; \mathrm{p}=0.000)$; emotional bond quality $(\mathrm{F}=672.93 ; \mathrm{p}=0.000)$; separation anxiety and dependence $(\mathrm{F}=485.62, \mathrm{p}=0.000)]$. The post hoc analysis indicated that the safe pattern differed significantly from the worried and disinvested patterns in the IEI factor and from the disinterested, frightened and worried patterns in the QEB and SAD factors. Through Graph 4 it is possible to visualize the results of the construction of the clusters.

Graph 4. Attachment Patterns in the Relationship with the Father

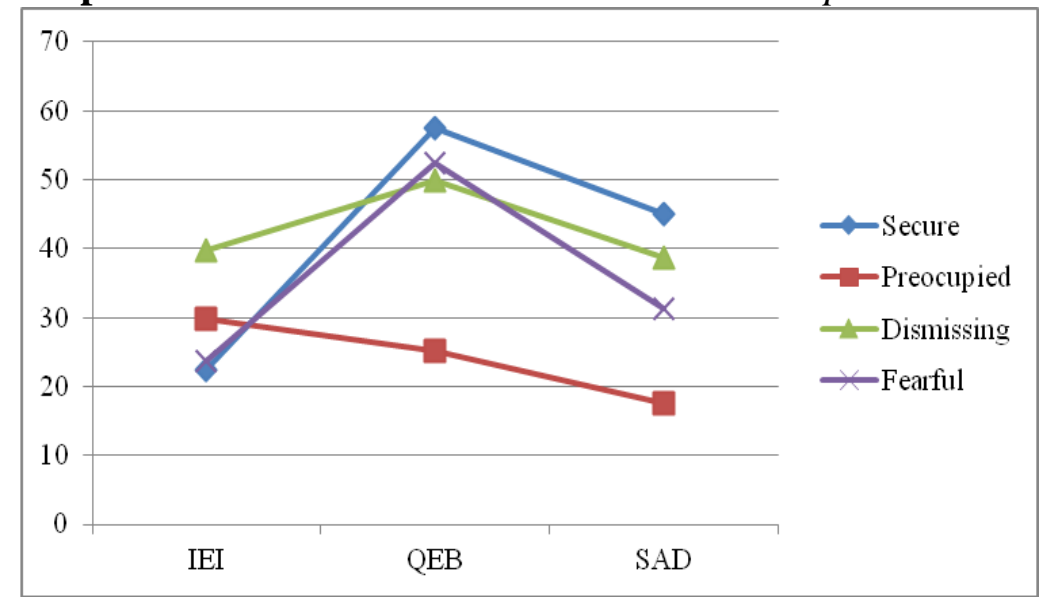

Note: Attachment factors in the relationship with the mother: IEI: Inhibition of Exploration and Individuality; QEB: Quality of Emotional Bond; SAD: Separation Anxiety and Dependency.

The differences in averages obtained from attachment patterns in relation with the father showed that the quality of emotional bonds is also interpretable in light of the Bartholomew model (Bartholomew and Horowitz 1991). 


\section{Attachment to Love Partner}

Graph 5. Dimensional Variability of the Attachment to the Love Partner

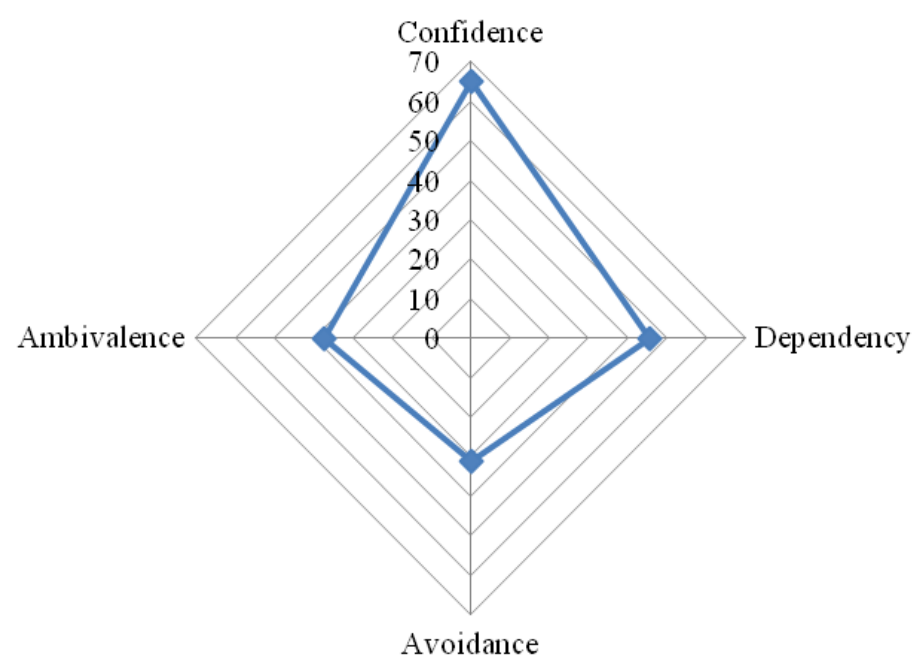

The application of a correlation allows us to observe statistically significant correlations between all factors and between each of these and the total scale. Correlation values range from very low $(r=0.024$, in the pair dependency ambivalence) and high ( $\mathrm{r}=0.701$, in the confidence - ambivalence pair). Some correlation values are negative indicating factor variations in the opposite direction (avoidance-confidence, avoidance-dependence).

In the analysis of common variance, we can observe in the confidence ambivalence pair a common variance of $78.6 \%$, in the confidence - avoidance pair a common variance of $56 \%$ indicating that these factors are supposed to evaluate aspects of related amorous bonding.

For the totality of the respondents, the following average scores of the relationship factors were found (Graph 5) with higher mean scores in the confidence factor $(\mathrm{M}=65.1 ; \mathrm{SD}=9.9)$.

Graph 6. Attachment Patterns to the Love Partner

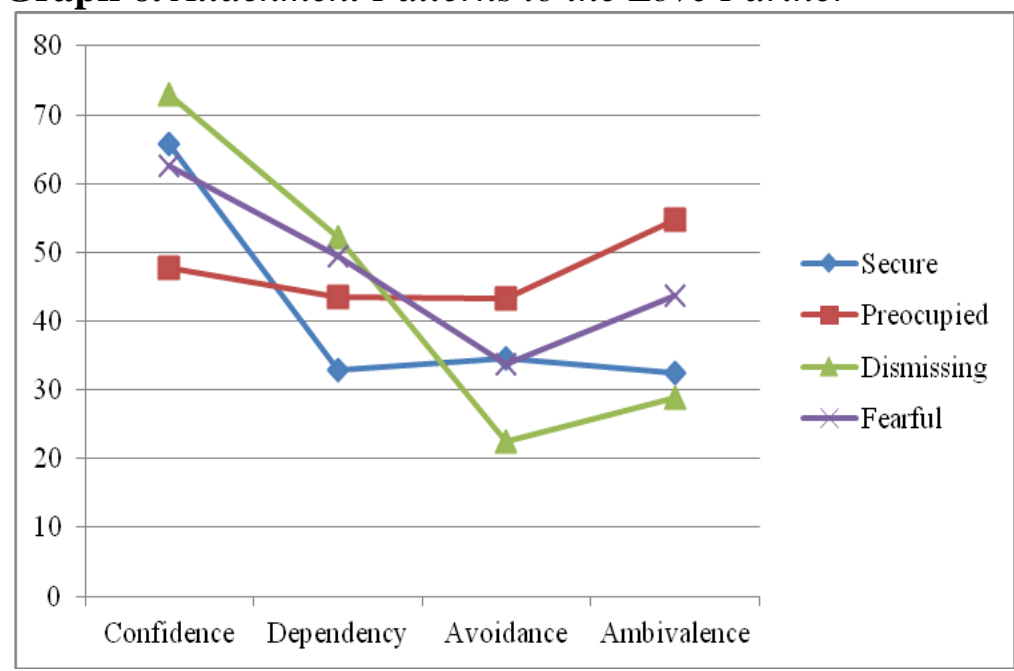


In the evaluation of the average results of the factors of the love attachment by gender, higher average results were found for the confidence factor between females $(M=65.3, S D=10.1)$ and for the dependence factors $(M=46.2(M=$ $34.1, \mathrm{SD}=10.1)$ and ambivalence $(\mathrm{M}=37.4, \mathrm{SD}=11.2)$ among males.

The application of the t-test for two independent samples allows the researchers to verify that there are only statistically significant differences between genders in relation to the avoidance factor $(t=3.515, \mathrm{p}=0.000)$. The difference of means resulting from ANOVA (One-way) demonstrated that the effect of the variable of attachment patterns on the means of the pairing factors was significant (confidence $=\mathrm{F}=445.86 ; \mathrm{p}=0.000)$; dependence $(\mathrm{F}=233.64, \mathrm{p}=0.000)$; The post hoc analysis indicated that the safe pattern differed significantly from the other patterns in confidence, dependence, and ambivalence factors, did not correlate with confidence intervals $(\mathrm{F}=265.96, \mathrm{p}=0.000, \mathrm{~F}=434.91, \mathrm{p}=0.000)$. Graph 6 shows the results of the construction of the clusters.

The bonding patterns constructed from the dimensions that assess the quality of attachment to the love partner also found groups theoretically framed in the Bartholomew model (Bartholomew and Horowitz 1991), statistically proving that they are significantly different from one another.

\section{Affective Temperament}

\section{Graph 7. Percentage of Individuals with Average Temperament}

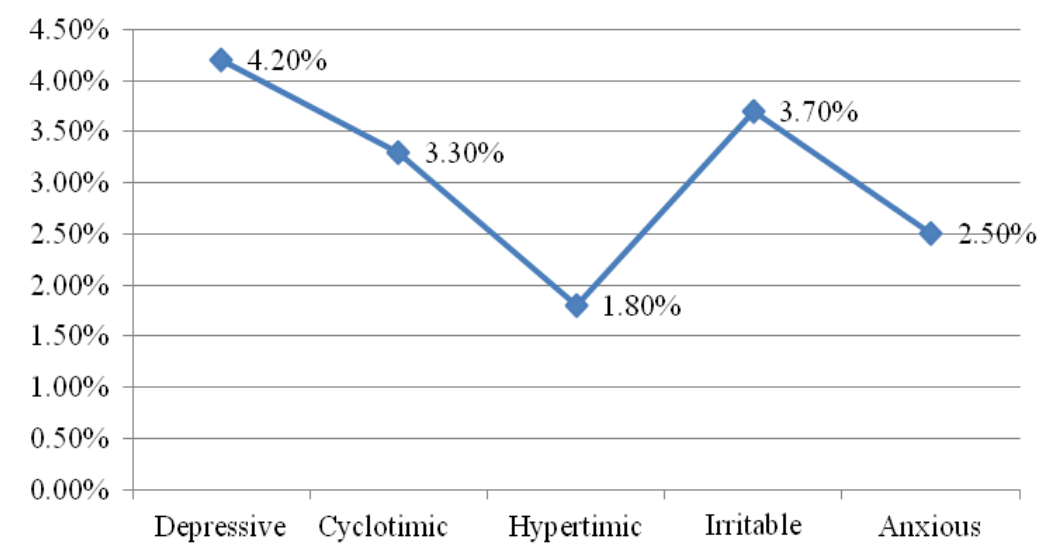

\section{Relationships between Attachment and Affective Temperament}

In the analysis of the correlation values between temperaments and the attachment factors in the relationship with the mother (Table 1) we have found statistically significant relationships between SAD and IEI factors and all temperaments and between the QEB factor and cyclothymic and irritable temperaments (unstable temperaments). These relations are expressed by negligible and weak level correlations. We found positive relationships between IEI and SAD factors and the depressive (stable) temperament, and between the cyclothymic, irritable and anxious (unstable) and the IEI and SAD factors, and the reverse relationships between hyperthymic temperament (stable) and factors such as IEI and SAD, and between cyclothymic and irritable (unstable) and QEB factor (Graph 7). 
Table 1. Correlation Values between Attachment Factors in the Relationship with the Mother and Affective Temperament

\begin{tabular}{|c|c|c|c|c|}
\hline \multicolumn{2}{|c|}{$\begin{array}{l}\text { Temperament/ } \\
\text { Factors }\end{array}$} & \multirow{2}{*}{$\begin{array}{c}\begin{array}{c}\text { Inhibition of exploration } \\
\text { and individuality }\end{array} \\
0.222^{* *}\end{array}$} & \multirow{2}{*}{$\begin{array}{c}\begin{array}{c}\text { Quality of } \\
\text { emotional bond }\end{array} \\
0.027\end{array}$} & \multirow{2}{*}{$\begin{array}{c}\text { Separation anxiety } \\
\text { and dependency } \\
0.246^{* *}\end{array}$} \\
\hline$\stackrel{n}{=}$ & Depressive & & & \\
\hline कू & Hyperthymic & $-0.094 * *$ & 0.061 & $-0.074^{*}$ \\
\hline \multirow{3}{*}{ 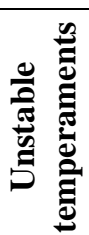 } & Cyclothymic & $0.359 * *$ & $-0.075^{*}$ & $0.164 * *$ \\
\hline & Irritable & $0.341^{* *}$ & $-0.116^{* * *}$ & $0.089 *$ \\
\hline & Anxious & $0.260 * *$ & 0.067 & $0.350^{* *}$ \\
\hline
\end{tabular}

Note: $*$ Significant correlation at $\mathrm{p} \leq 0.05$ and $* *$ Significant correlation at $\mathrm{p} \leq 0.01$.

Table 2. Relationship between Attachment Patterns in the Relationship with the Mother and Stable and Unstable Temperaments

\begin{tabular}{|c|c|c|c|c|c|c|c|}
\hline \multirow{2}{*}{\multicolumn{2}{|c|}{$\begin{array}{c}\text { Temperament/ } \\
\text { Attachment Patterns }\end{array}$}} & \multicolumn{4}{|c|}{ Attachment Pattern to the Mother } & \multirow{2}{*}{$\begin{array}{c}\text { Total } \\
(\mathbf{N})\end{array}$} & \multirow{2}{*}{$\begin{array}{c}\text { Chi- } \\
\text { Square } \\
\left(\chi^{2}\right)\end{array}$} \\
\hline & & Secure & Preocupied & Dismissing & Fearful & & \\
\hline \multirow{2}{*}{ 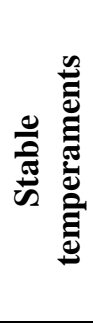 } & $\begin{array}{c}\text { Dominant } \\
\text { Depressive } \\
\text { Temperament } \\
(\mathrm{Z} \text { score }>2 \mathrm{SD})\end{array}$ & $\begin{array}{c}9 \\
(28.1 \%)\end{array}$ & $\begin{array}{c}3 \\
(9.4 \%)\end{array}$ & $\begin{array}{c}16 \\
(50 \%)\end{array}$ & $\begin{array}{c}4 \\
(12.5 \%)\end{array}$ & 32 & $\begin{array}{l}12.244(3) \\
p=0.007 * *\end{array}$ \\
\hline & $\begin{array}{c}\text { Dominant } \\
\text { Hyperthymic } \\
\text { Temperament } \\
(Z \text { Score }>2 S D)\end{array}$ & $\begin{array}{c}4 \\
(28.6 \%)\end{array}$ & $\begin{array}{c}5 \\
(35.7 \%)\end{array}$ & $\begin{array}{c}2 \\
(14.3 \%)\end{array}$ & $\begin{array}{c}3 \\
(21.4 \%)\end{array}$ & 14 & $\begin{array}{l}2.982(3) \\
p=0.394\end{array}$ \\
\hline \multirow{3}{*}{ 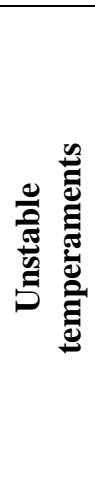 } & $\begin{array}{c}\text { Dominant } \\
\text { cyclothymic } \\
\text { Temperament } \\
(\mathrm{Z} \text { Score }>2 \mathrm{SD})\end{array}$ & $\begin{array}{c}5 \\
(20 \%)\end{array}$ & $\begin{array}{c}3 \\
(12 \%)\end{array}$ & $\begin{array}{c}11 \\
(44 \%)\end{array}$ & $\begin{array}{c}6 \\
(24 \%)\end{array}$ & 25 & $\begin{array}{l}11.901(3) \\
p=0.008 * *\end{array}$ \\
\hline & $\begin{array}{c}\text { (Dominant } \\
\text { Irritable } \\
\text { Temperament } \\
(\mathrm{Z} \text { Score }>2 \mathrm{SD})\end{array}$ & $\begin{array}{c}9 \\
(32.1 \%)\end{array}$ & $\begin{array}{c}1 \\
(3.6 \%)\end{array}$ & $\begin{array}{c}12 \\
(42.9 \%)\end{array}$ & $\begin{array}{c}6 \\
(21.4 \%)\end{array}$ & 28 & $\begin{array}{l}12.663(3) \\
p=0.005 * *\end{array}$ \\
\hline & $\begin{array}{c}\text { Dominant } \\
\text { Anxious } \\
\text { Temperament } \\
(\mathrm{Z} \text { Score }>2 \mathrm{SD})\end{array}$ & $\begin{array}{c}7 \\
(36.8 \%)\end{array}$ & $\begin{array}{c}2 \\
(10.5 \%)\end{array}$ & $\begin{array}{c}9 \\
(47.4 \%)\end{array}$ & $\begin{array}{c}1 \\
(5.3 \%)\end{array}$ & 19 & $\begin{array}{l}6.008(3) \\
p=0.111\end{array}$ \\
\hline
\end{tabular}

Note: $*$ Significant correlation at $\mathrm{p} \leq 0.05$ and $* *$ Significant correlation at $\mathrm{p} \leq 0.01$.

The Simple Linear Regression model (SLR) enabled us to observe the contribution of the attachment factors in the relationship with the mother for the variance of each temperament.

We can thus assert that in the case of depressive temperament the IEI factor contributes to $4.4 \%\left(\mathrm{R}^{2}=0.44\right)$ of the variance, and the SAD factor to $6 \%\left(\mathrm{R}^{2}=\right.$ $0.60)$ of the variance. 
For the hyperthymic temperament these values are: IEI $-0.9 \%\left(\mathrm{R}^{2}=0.09\right)$. For the cyclothymic temperament the values are: IEI $-12.9 \%\left(\mathrm{R}^{2}=0.129\right)$ and $\mathrm{SAD}-2.1 \%\left(\mathrm{R}^{2}=0.021\right)$.

For the irritable temperament these values are: IEI $-11.6 \%\left(\mathrm{R}^{2}=0.116\right)$ and $\mathrm{SAD}-0.5 \%(0.05)$. For the anxious temperament the values are IEI $-5.8 \%\left(\mathrm{R}^{2}=\right.$ $0.058)$ and $\mathrm{SAD}-12.3 \%\left(\mathrm{R}^{2}=0.123\right)$.

In the study of the association between attachment patterns in the relationship with the mother and affective temperament, we can observe higher frequencies of individuals with stable dominant temperaments ( $Z$ score $>2 S D)$ among individuals with dismissing attachment pattern for the depressive temperament and among individuals with a preoccupied attachment pattern for hyperthymic temperament.

This association between a depressive temperament and a dismissing pattern is statistically significant.

We can also observe higher frequencies of individuals with dominant unstable (cyclothymic and irritable) temperaments ( $Z$ score $>2 S D$ ) among individuals with dismissing pattern of attachment, this association being statistically significant (Table 2).

In the analysis of the correlation values between the temperaments and the attachment factors to the father (Table 3), we found statistically significant relationships between the IEI factor and all temperaments (inverse relationship between IEI factor and the hyperthymic), between QEB factor and the cyclothimic and irritable temperaments (inverse relationship) and hyperthymic temperament and between the SAD factor and the depressive, cyclothymic and anxious temperaments.

Table 3. Correlation Values between Attachment Factors in the Relationship with the Father and Affective Temperament

\begin{tabular}{|c|c|c|c|c|}
\hline \multicolumn{2}{|c|}{ Temperament/Factors } & \multirow{2}{*}{$\begin{array}{c}\begin{array}{c}\text { Inhibition of } \\
\text { exploration and } \\
\text { individuality }\end{array} \\
0.199^{* *}\end{array}$} & \multirow{2}{*}{$\begin{array}{c}\begin{array}{c}\text { Quality of } \\
\text { emotional bond }\end{array} \\
-0.035\end{array}$} & \multirow{2}{*}{$\begin{array}{r}\begin{array}{r}\text { Separation } \\
\text { anxiety and } \\
\text { dependency }\end{array} \\
0.166^{* *}\end{array}$} \\
\hline 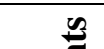 & Depressive & & & \\
\hline कू & Hyperthymic & $-0.082 *$ & $0.102 * *$ & -0.008 \\
\hline \multirow{3}{*}{ 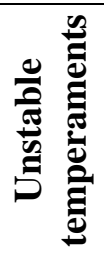 } & Cyclothymic & $0.294 * *$ & $-0.084 *$ & $0.114 * *$ \\
\hline & Irritable & $0.283 * *$ & $-0.113 * *$ & 0.052 \\
\hline & Anxious & $0.249^{* *}$ & -0.015 & $0.262^{* *}$ \\
\hline
\end{tabular}

Note: *Significant correlation at $\mathrm{p} \leq 0.05$ and $* *$ Significant correlation at $\mathrm{p} \leq 0.01$. 
Table 4. Relationship between Attachment Patterns in the Relationship with the Father and Stable and Unstable Temperaments

\begin{tabular}{|c|c|c|c|c|c|c|c|}
\hline \multirow{2}{*}{\multicolumn{2}{|c|}{$\begin{array}{c}\text { Temperament/ } \\
\text { Attachment Patterns }\end{array}$}} & \multicolumn{4}{|c|}{ Attachment Pattern to the Father } & \multirow{2}{*}{$\begin{array}{c}\text { Total } \\
(\mathbf{N})\end{array}$} & \multirow{2}{*}{$\begin{array}{c}\text { Chi- } \\
\text { Square } \\
\left(\chi^{2}\right)\end{array}$} \\
\hline & & \multirow{2}{*}{\begin{tabular}{|c|}
$\begin{array}{c}\text { Secure } \\
(\mathbf{N})\end{array}$ \\
6 \\
$(18.8 \%)$
\end{tabular}} & \multirow{2}{*}{$\begin{array}{c}\begin{array}{c}\text { Preocupied } \\
\text { (N) }\end{array} \\
5 \\
(15.6 \%)\end{array}$} & \multirow{2}{*}{\begin{tabular}{|c|}
$\begin{array}{c}\text { Dismissing } \\
(\mathbf{N})\end{array}$ \\
15 \\
$(46.9 \%)$
\end{tabular}} & \multirow{2}{*}{\begin{tabular}{|c|}
$\begin{array}{c}\text { Fearful } \\
(\mathbf{N})\end{array}$ \\
6 \\
$(18.8 \%)$
\end{tabular}} & & \\
\hline \multirow{2}{*}{ 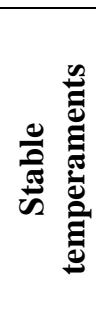 } & $\begin{array}{c}\text { Dominant } \\
\text { Depressive } \\
\text { Temperament } \\
(\mathrm{Z} \text { Score }>2 \mathrm{SD})\end{array}$ & & & & & 32 & $\begin{array}{l}13.421(3) \\
p=0.004 * *\end{array}$ \\
\hline & $\begin{array}{c}\text { Dominant } \\
\text { Hyperthymic } \\
\text { Temperament } \\
(Z \text { Score }>2 S D)\end{array}$ & $\begin{array}{c}5 \\
(35.7 \%)\end{array}$ & $\begin{array}{c}1 \\
(7.1 \%)\end{array}$ & $\begin{array}{c}4 \\
(28.6 \%)\end{array}$ & $\begin{array}{c}4 \\
(28.6 \%)\end{array}$ & 14 & $\begin{array}{l}0.279(3) \\
p=0.964\end{array}$ \\
\hline \multirow{3}{*}{ 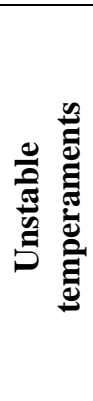 } & $\begin{array}{c}\text { Dominant } \\
\text { Cyclothymic } \\
\text { Temperament } \\
(Z \text { Score }>2 S D)\end{array}$ & $\begin{array}{c}5 \\
(20 \%)\end{array}$ & $\begin{array}{c}4 \\
(16 \%)\end{array}$ & $\begin{array}{c}9 \\
(36 \%)\end{array}$ & $\begin{array}{c}7 \\
(28 \%)\end{array}$ & 25 & $\begin{array}{l}4.847(3) \\
p=0.183\end{array}$ \\
\hline & $\begin{array}{c}\text { (Dominant Irritable } \\
\text { Temperamen } \\
\text { (Z Score }>2 S D)\end{array}$ & $\begin{array}{c}9 \\
(32.1 \%)\end{array}$ & $\begin{array}{c}2 \\
(7.1 \%)\end{array}$ & $\begin{array}{c}11 \\
(39.3 \%)\end{array}$ & $\begin{array}{c}6 \\
(21.4 \%)\end{array}$ & 28 & $\begin{array}{l}4.077(3) \\
p=0.253\end{array}$ \\
\hline & $\begin{array}{l}\text { Dominant Anxious } \\
\text { Temperament } \\
\text { (Z Score }>2 S D)\end{array}$ & $\begin{array}{c}5 \\
(26.3 \%)\end{array}$ & $\begin{array}{c}4 \\
(21.1 \%)\end{array}$ & $\begin{array}{c}8 \\
(42.1 \%)\end{array}$ & $\begin{array}{c}2 \\
(10.5 \%)\end{array}$ & 19 & $\begin{array}{c}9.652(3) \\
p=0.022 * *\end{array}$ \\
\hline
\end{tabular}

Note: *Significant correlation at $\mathrm{p} \leq 0.05$ and ${ }^{*}$ Significant correlation at $\mathrm{p} \leq 0.01$.

The Simple Linear Regression model (MRL) enabled us to observe the contribution of the attachment factors in the relationship with the father for the variance of each temperament. Therefore, we can state that in the case of depressive temperament the IEI factor contributed to $4 \%\left(\mathrm{R}^{2}=0.040\right)$ of the variance, factor $\mathrm{QEB}$ to $1.7 \%\left(\mathrm{R}^{2}=0.017\right)$ of the variance and SAD factor to $2.7 \%$ $\left(\mathrm{R}^{2}=0.027\right)$.

For the hyperthymic temperament those values are: IEI $-1 \%\left(\mathrm{R}^{2}=0.010\right)$ and $\mathrm{SAD}-1 \%\left(\mathrm{R}^{2}=0.010\right)$. For the cyclothymic temperament those values are: IEI $8.7 \%(\mathrm{R} 2=0.087), \mathrm{QEB}-1.4 \%\left(\mathrm{R}^{2}=0.014\right)$ and $\mathrm{SAD}-1.2 \%\left(\mathrm{R}^{2}=0.012\right)$. For the irritable temperament those values are IEI $-8 \%\left(\mathrm{R}^{2}=0.080\right)$. For the anxious temperament the values are IEI $-2.9 \%\left(\mathrm{R}^{2}=0.029\right), \mathrm{QEB}-6.2 \%\left(\mathrm{R}^{2}=0.062\right)$ and $\mathrm{SAD}-6.9 \%\left(\mathrm{R}^{2}=0.069\right)$.

In the study of the association between patterns of attachment in the relationship with the father and affective temperament, we are able to observe higher frequencies of individuals with dominant unstable temperaments ( $Z$ score $>2 \mathrm{SD}$ ) among individuals with dismissing attachment patterns.

With regard to stable temperaments, the highest frequency of individuals with a hyperthymic temperament is to be found among individuals with a secure attachment pattern; meanwhile, the highest frequency of individuals with a depressive temperament is among individuals with a dismissing attachment pattern. This association is statistically significant in depressive and anxious temperaments and dismissing pattern (Table 4).

In the analysis of the correlation values between the temperaments and the loving attachment factors (Table 5), we found statistically significant relationships between the dependence and ambivalence factors and all temperaments, between 
the confidence factor and the depressive, cyclothymic, irritable and anxious temperaments and between the avoidance factor and the cyclothymic and irritable temperaments. These relations were expressed by negligible and weak level correlations, revealing positive and negative relationships.

Table 5. Correlation Values between Factors of Attachment to the Love Partner and Affectionate Temperament

\begin{tabular}{|c|c|c|c|c|c|}
\hline \multicolumn{2}{|c|}{ Temperament/Factors } & Confidence & Dependency & Avoidance & Ambivalence \\
\hline \multirow{2}{*}{ 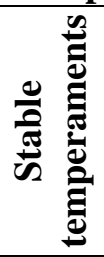 } & Depressive & $-0.073 *$ & $0.303 * *$ & -0.024 & $0.206 * *$ \\
\hline & Hyperthymic & 0.003 & $-0.146 * *$ & 0.030 & $-0.101 * *$ \\
\hline \multirow{3}{*}{ 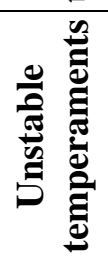 } & Cyclothymic & $-0.171 * *$ & $0.168^{* * *}$ & $0.119 * *$ & $0.345 * *$ \\
\hline & Irritable & $-0.195 * *$ & $0.139 * *$ & $\mathbf{0 . 1 1 8}^{* * *}$ & $0.345^{* *}$ \\
\hline & Anxious & $-0.091^{*}$ & 0.339** & -0.058 & $0.265^{* * *}$ \\
\hline
\end{tabular}

Note: *Significant correlation at $\mathrm{p} \leq 0.05$ and $* *$ Significant correlation at $\mathrm{p} \leq 0.01$.

Table 6. Relationship between Patterns of Loving Attachment and Stable and Unstable Temperaments

\begin{tabular}{|c|c|c|c|c|c|c|c|}
\hline \multirow{2}{*}{\multicolumn{2}{|c|}{$\begin{array}{c}\text { Temperament/ } \\
\text { Patterns of Attachment }\end{array}$}} & \multicolumn{4}{|c|}{ Pattern of Loving Attachment } & \multirow{2}{*}{$\begin{array}{l}\text { Total } \\
(\mathbf{N})\end{array}$} & \multirow{2}{*}{$\begin{array}{c}\text { Chi- } \\
\text { Square } \\
\left(\chi^{2}\right)\end{array}$} \\
\hline & & \multirow{2}{*}{$\begin{array}{c}\begin{array}{c}\text { Secure } \\
(\mathbf{N})\end{array} \\
1 \\
(3.1 \%)\end{array}$} & \multirow{2}{*}{$\begin{array}{c}\begin{array}{c}\text { Preocupied } \\
(\mathbf{N})\end{array} \\
2 \\
(6.3 \%)\end{array}$} & \multirow{2}{*}{$\begin{array}{c}\begin{array}{c}\text { Dismissing } \\
(\mathbf{N})\end{array} \\
8 \\
(25 \%)\end{array}$} & \multirow{2}{*}{\begin{tabular}{|c|}
$\begin{array}{c}\text { Fearful } \\
(\mathrm{N})\end{array}$ \\
21 \\
$(65.6 \%)$
\end{tabular}} & & \\
\hline 을 & $\begin{array}{c}\text { Dominant } \\
\text { Depressive } \\
\text { Temperament } \\
\text { (Z Score }>2 S D)\end{array}$ & & & & & 32 & $\begin{array}{l}25.040(3) \\
p=0.000 * *\end{array}$ \\
\hline 离 & $\begin{array}{c}\text { Dominant } \\
\text { Hyperthymic } \\
\text { Temperament } \\
(Z \text { Score }>2 S D)\end{array}$ & $\begin{array}{c}6 \\
(24 \%)\end{array}$ & $\begin{array}{c}7 \\
(28 \%)\end{array}$ & $\begin{array}{c}3 \\
(12 \%)\end{array}$ & $\begin{array}{c}9 \\
(36 \%)\end{array}$ & 25 & $\begin{array}{l}9.068(3) \\
p=0.028^{*}\end{array}$ \\
\hline \multirow{3}{*}{ 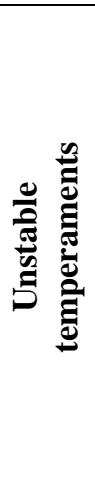 } & $\begin{array}{c}\text { Dominant } \\
\text { Cyclothymic } \\
\text { Temperament } \\
(Z \text { Score }>2 S D)\end{array}$ & $\begin{array}{c}4 \\
(28.6 \%)\end{array}$ & $\begin{array}{c}1 \\
(7.1 \%)\end{array}$ & $\begin{array}{c}5 \\
(35.7 \%)\end{array}$ & $\begin{array}{c}4 \\
(28.6 \%)\end{array}$ & 14 & $\begin{array}{l}0.489(3) \\
p=0.921\end{array}$ \\
\hline & $\begin{array}{c}\text { (Dominant } \\
\text { Irritable } \\
\text { Temperamen } \\
\text { (Z Score }>2 S D)\end{array}$ & $\begin{array}{c}6 \\
(24 \%)\end{array}$ & $\begin{array}{c}7 \\
(28 \%)\end{array}$ & $\begin{array}{c}3 \\
(12 \%)\end{array}$ & $\begin{array}{c}9 \\
(36 \%)\end{array}$ & 25 & $\begin{array}{l}9.068(3) \\
p=0.028^{*}\end{array}$ \\
\hline & $\begin{array}{c}\text { Dominant } \\
\text { Anxious } \\
\text { Temperament } \\
\text { (Z Score }>2 S D)\end{array}$ & $\begin{array}{c}0 \\
(0 \%)\end{array}$ & $\begin{array}{c}6 \\
(31.6 \%)\end{array}$ & $\begin{array}{c}4 \\
(21.1 \%)\end{array}$ & $\begin{array}{c}9 \\
(47.4 \%)\end{array}$ & 19 & $\begin{array}{l}13.652(3) \\
p=0.003 * *\end{array}$ \\
\hline
\end{tabular}

Note: *Significant correlation at $\mathrm{p} \leq 0.05$ and ${ }^{* *}$ Significant correlation at $\mathrm{p} \leq 0.01$.

The Simple Linear Regression model (SLR) enabled us to observe the contribution of the factors of attachment to the love partner for the variance of each temperament. 
Thus, we can state that in the case of the depressive temperament the dependency factor contributes to $9.2 \%\left(\mathrm{R}^{2}=0.092\right)$ of the variance and the ambivalence factor to $3.3 \%\left(\mathrm{R}^{2}=0.033\right)$.

For the hyperthymic temperament these values are: dependency $-2.1 \%\left(\mathrm{R}^{2}=\right.$ $0.021)$ and ambivalence $-0.8 \%\left(R^{2}=0.008\right)$. For the cyclothymic temperament the values are: dependency $-2 \%\left(\mathrm{R}^{2}=0.020\right)$ and ambivalence $-11.9 \%\left(\mathrm{R}^{2}=\right.$ $0.119)$. For the irritable temperament these values are: dependency $-1.2 \%\left(\mathrm{R}^{2}=\right.$ $0.012)$ and ambivalence $-11.9 \%\left(\mathrm{R}^{2}=0.119\right)$. For the anxious temperament the values are: dependency $-11.5 \%\left(\mathrm{R}^{2}=0.115\right)$, avoidance $-0.8 \%\left(\mathrm{R}^{2}=0.008\right)$ and ambivalence $-5.7 \%\left(\mathrm{R}^{2}=0.057\right)$.

In the study of the association between patterns of loving attachment and affectionate temperament, we can observe higher frequencies of individuals with a stable (depressive and hyperthymic) dominant temperaments ( $\mathrm{Z}$ score $>2 \mathrm{SD}$ ) among individuals with a fearful pattern of attachment, this association being statistically significant.

We can also observe higher frequencies of individuals with a dominant cyclothymic temperaments ( $\mathrm{Z}$ score $>2 \mathrm{SD}$ ) among individuals with a dismissing attachment pattern and higher frequencies of individuals with a dominant irritable and anxious temperament ( $\mathrm{Z}$ score $>2 \mathrm{SD}$ ) among individuals with a fearful attachment pattern, this association being statistically significant in the case of anxious temperament (Table 6). In short, it has been found that with regard to the relation between the attachment factors and affective temperaments:

- The attachment factor in the relationship with the mother that mostly contributes to the variance of temperaments is the IEI factor, contributing mostly to the variance of the cyclothymic (12.9\%) and irritable temperament $(11.6 \%)$;

- The attachment factor in the relationship with the father that mostly contributes to the variance of temperaments is the IEI factor, with the greatest contribution to the variance of cyclothymic (8.7\%) and irritable temperament $(8 \%)$;

- The attachment factor to the love partner that mostly contributes to the variance of temperaments is the dependency factor, with greatest contribution to the variance of the anxious (11.5\%) and depressive (9.2\%);

- As for the attachment in the relationship with the mother, the depressive temperament (stable) and the unstable temperaments (cyclothymic, irritable and anxious) proved to be dominant in the dismissing pattern and the hyperthymic (stable) is dominant in the preoccupied;

- As for the attachment in the relationship with the father, the depressive temperament (stable) and the unstable temperaments (cyclothymic, irritable and anxious) proved to be dominant in the dismissing pattern and the hyperthymic (stable) in the secure;

- As for the attachment to the love partner, the stable temperaments (depressive and hyperthymic) and the irritable and anxious temperaments (unstable) proved to be dominant in the fearful pattern and the cyclothymic temperament in the dismissing pattern. 


\section{Discussion}

It is suggested that girls invest more in the relationship with mothers than with fathers, although they are more dependent on mothers, as compared with boys. There seems to be evidence that the quality of the emotional bond in girls is more robust with respect to both parental elements, and hence the separation anxiety and dependency levels found were also higher.

Girls have shown higher levels of confidence and ambivalence in love relationships than boys, and the latter show a higher degree of avoidance and dependency. These results require a robust theoretical framework that indicates that the perceptions of romantic relationships in adolescence are differentiated by gender and that this differentiation is more positive and invested in by girls.

From the various results, we highlight those that indicate that the depressive temperament has anxiety characteristics and that the anxious temperament has cyclothymic and depressive characteristics. Each maintains its individuality, as temperament is an individual characteristic, but is not mutually exclusive. The researchers can justify significant differences between temperaments with clear contact points from a psychopathological point of view.

There will be temperamental characteristics more attributable to one gender than to the other. The cyclothymic, depressive and anxious temperaments are more characteristic of females, and the irritable and hyperthymic temperaments appear mostly in males, which has been corroborated by other studies.

According to MacDonald et al. (2013), significant, robust correlations were found between attachment anxiety and several negative affective temperaments (dysthymic and cyclothymic).

The current study highlights the statistically significant relationship between cyclothymic and irritable temperaments (unstable temperaments) and all the attachment factors to the love partner, with emphasis on the negative relationship between the cyclothymic temperament and the confidence factor, revealing a reverse relationship. These results, among others, suggest a depreciation of the confidence factor for individuals with cyclothymic temperament, with a similar conclusion applying to the same factor and to the other temperaments.

As for the loving attachment patterns, we found statistically significant associations between depressive, hyperthymic (stable) and anxious (unstable) temperaments and the fearful pattern, as well as between this latter pattern and the irritable temperament (unstable).

\section{Conclusion}

Regarding the study of parental attachment (mother and father), the researchers found significant associations between unstable temperaments and dismissing patterns. This suggests that individuals with positive self-representation and negative models of others have unstable temperaments as dominant.

Considering the attachment in the relationship with the mother, the depressive (stable) and unstable temperaments (cyclothymic, irritable and anxious) proved to 
be dominant in the dismissing pattern and the hyperthymic (stable) in the preoccupied.

With regard to the attachment in the relationship with the father, the depressive (stable) and unstable temperaments (cyclothymic, irritable and anxious) proved to be dominant in the dismissing pattern and the hyperthymic (stable) in the secure.

Concerning the love attachment, the results highlight significant associations with both stable or unstable temperaments and the preoccupied pattern, which suggests an unclear association between temperaments (from the point of view of its stability) and the individuals with a preoccupied pattern.

Temperament influences the types of experiences we engage in and how we instinctively react to them. Thus, it is clear that temperament and character interact and influence each other. It is not always easy to distinguish what derives from character and what comes from temperament.

The relationship between excessive temperament types and attachment patterns proved to be a research question that can clarify certain observable behaviours, pathways and affective choices.

However, there were some limitations to this study, such as a cross-sectional study design, while longitudinal studies are more informative. Moreover, the limited sample size (making exploration of sex differences in these associations impossible) and the use of a nonclinical population hinder the generalization of the results. This last observation can be a good starting point for future studies on this subject.

\section{Acknowledgments}

Special thanks to Prof. Maria Luísa Figueira and Prof. Purificação Horta from the Medical Faculty of Lisbon and to Prof. Emílio Salgueiro for their supervision on my PhD.

\section{References}

Ainsworth MDS, Bowlby J (1991) An etiological approach to personality development. American Psychologist 46: 331-341.

Akiskal KK, Savino M, Akiskal HS (2005a) TEMPS: Temperaments profiles in physicians, lawyers, managers, industrialists, architects, journalists, and artist: a study in psychiatric outpatients. Journal of Affective Disorders 85: 201-206.

Akiskal HS, Akiskal KK, Haykal R, Manning JS, Connor P (2005b) TEMPS-A: progress towards validation of a self-rated clinical version of the temperament evaluation of the Memphis, Pisa, Paris, and San Diego Autoquestionnaire. Journal of Affective Disorders 85: 3-16.

Akiskal HS, Akiskal KK (2005a) TEMPS: Temperament Evaluation of Memphis, Pisa, Paris and San Diego. Journal of Affective Disorders 85(1-2).

Akiskal KK, Akiskal HS (2005b) The theoretical underpinnings of affective temperaments: implications for evolutionary foundations of bipolar disorder and human nature. Journal of Affective Disorders 85: 231-239. 
Akiskal HS, Placidi GF, Signoretta S, Liguori A, Gervasi R, Maremmani I et al. (1998) TEMPS-I: delineating the most discriminant traits of cyclothymic, depressive, irritable and hyperthymic temperaments in a nonpatient population. Journal of Affective Disorders 51: 7-19.

Akiskal HS (1994) Dysthymic and cyclothymic depressions: therapeutic considerations. Journal of Clinical Psychiatry 55: 46-52.

Akiskal HS (1985) Anxiety: definition, relationship to depression, and proposal for an integrative model. In A Tuma, J Maser (Eds.), Anxiety and the Anxiety Disorders (pp. 787-797). Hillsdale, NJ: Lawrence Erlbaum.

Allport GW (1961) Pattern and growth in personality. New York: Holt, Rinehart \& Winston.

Bartholomew K, Shaver PR (1998) Methods of assessing adult attachment: Do they converge? In JA Simpson, WS Rholes (Eds.), Attachment theory and close relationships (pp. 25-45). New York: Guilford Press.

Bartholomew K (1996) Peer Attachment Interview. (Manuscript Non Published).

Bartholomew K, Horowitz L (1991) Attachment styles among young adults: A test of four-category model. Journal of Personality and Social Psychology 61: 226-244.

Bartholomew K (1990) Avoidance of intimacy: An attachment perspective. Journal of Social and Personal Relationships 7: 147-178.

Bowlby J (1984a) Psicologia e Pedagogia - Apego: volume I (Psychology and Pedagogy - Attachment: volume I). São Paulo: Martins e Fontes Editora.

Bowlby J (1984b) Psicologia e Pedagogia - Separação, angústia e raiva: volume II (Psychology and Pedagogy - Separation, anguish and anger: volume II). São Paulo: Martins e Fontes Editora.

Bowlby J (1980) Attachment and loss. Vol. 3. Loss, sadness and depression. New York: Basic Books.

Bowlby J (1979) The making and breaking of affectional bonds. London: Routledge.

Bowlby, J. (1978a). Attachment and Loss, Vol.1. Attachment. Harmondsworth: Penguin Books.

Bowlby, J. (1978b). Attachment and Loss, Vol. 2. Separation, anxiety and anger. Harmondsworth: Penguin Books.

Cloninger C, Svrakic D, Przybeck T (1993) A psychobiological model of temperament and character. Archives of General Psychiatry 50(12): 975-990.

Figueira ML, Caeiro L, Ferro A, Severino L, Duarte PM, Abreu M et al. (2008) Validation of the Temperament Evaluation of Memphis, Pisa, Paris and San Diego (TEMPS-A): Portuguese-Lisbon version. Journal of Affective Disorders 111: 193-203.

Figueira ML, Caeiro L, Ferro A, Cordeiro R, Duarte P, Akiskal HS et al. (2009) Temperament in Portuguese university students as measured by TEMPS-A: implications for professional choice. Journal of Affective Disorders 123(1): 30-35.

Kraepelin E (1921) Manic-Depressive Insanity and Paranoia. Edinburgh: E\&S.

Kraepelin E (1913/1919) Dementia praecox and paraphrenia (trad. Barclay RM). Edimburg: E.S. Livingstone.

Lara DR (2006) $O$ modelo de medo e raiva para transtornos do humor, do comportamento e da personalidade (The fear and anger model for mood, behavior, and personality disorders). Porto Alegre: Revolução de Idéias.

MacDonald K, Berlow R, Thomas ML (2013) Attachment, affective temperament, and personality disorders: A study of their relationships in psychiatric outpatients. Journal of Affective Disorders 151(3): 932-941.

Matos PM, Almeida HM, Costa ME (1998, June). Dimensions of attachment to mother and to father in portuguese adolescents. Poster presented at the VI Biennial Congress of the European Association for Research on Adolescence, Budapest, Hungary. 
Matos PM, Costa ME (2001a) Questionnaire of Bonding to Father and Mother: Version III. Document provided by the authors.

Matos PM, Costa ME (2001b) Amorous Bonding Questionnaire: Research Version III. (Manuscript Non Published).

Matos PM, Costa ME (2006) Vinculação aos pais e ao par romântico em adolescentes (Linking to parents and the romantic couple in adolescents). Psicologia 20: 97-126.

Matos PM, Almeida HM, Costa ME (1997) The questionnaire of attachment to father and mother: development and validation studies (Manuscript Non Published).

Matos PM, Barbosa S, Costa ME (2001) Avaliação da vinculação amorosa em adolescentes e jovens adultos: Construção de um instrumento e estudos de validação (Assessment of love affiliation in adolescents and young adults: Construction of an instrument and validation studies). Revista Oficial de la Asociación Iberoamericana de Diagnóstico Y Evaluación Psicológica 11: 93-109.

Matos PM, Barbosa S, Almeida HM, Costa M (1999) The Parental Attachment and Identity in Portuguese Late Adolescents. Journal of Adolescence 22(6): 805-818.

Moura O, Matos PM (2008) Vinculação aos pais, divórcio e conflito interparental (Relationship to parents, divorce and interparental conflict). Psicologia XXII(1): 127 152.

Vahip S, Kesebir S, Alkan M, Yazic O, Akiskal K, Akiskal HS (2005) Affective temperaments in clinically-well subjects in Turkey: initial psychometric data on the TEMPS-A. Journal of Affective Disorders 85: 113-125. 